
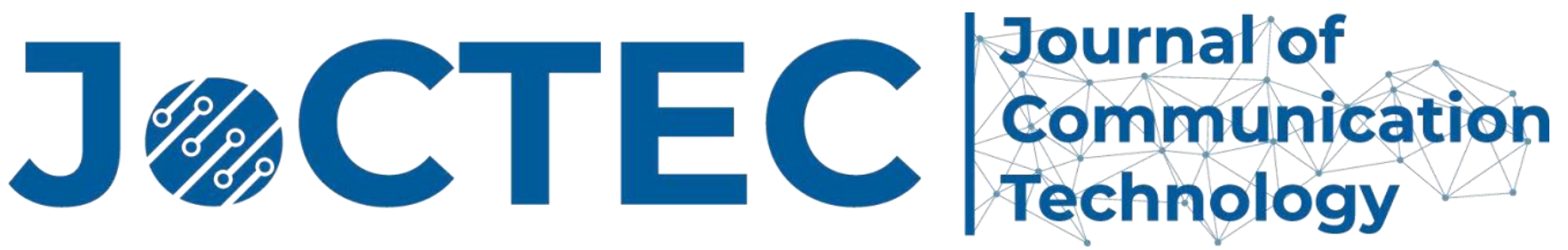

Published by the Communication Technology Division

of the Association for Education in Journalism and Mass Communication

Peer review: This article has been subject to a double-blind peer review process

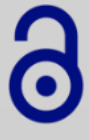

open access

JoCTEC is an open access journal meaning that all content is freely available without charge to the user or their institution. Users are allowed to read, download, copy, distribute, print, search, or link to the full texts of the articles, or use them for any other lawful purpose, without asking prior permission from the publisher or the author.

Open access is an ongoing publication practice that differs from the traditional manner academic journals are published and then received by the reading public. In Open Access publication model neither readers nor a reader's institution are charged for access to articles or other resources. We ask that users in turn give proper citation of the original publication or link to the full texts of these articles for any noncommercial purposes A subscription to the journal in which these articles are published is not required.

\section{User Experience (UX) Matters: What are the Most Desired Skills in the UX Designer and UX Researcher Job Ads}

\author{
Ruoxu Wanga, Jin Yang ${ }^{\text {a }}$, and Louis Asser \\ aUniversity of Memphis, Memphis, Tennessee, USA \\ Correspondence: rwang4@memphis.edu
}

\begin{abstract}
A content analysis study $(N=200)$ was conducted to examine the most desired skills required in UX designers and UX researchers job ads on the LinkedIn platform. Results showed the visual interface design skill is the most needed design skill for UX designers. For UX researchers, the research skills of usability lab studies, moderated remote usability studies, usability benchmarking, and interviews are most needed. Information Technology \& Service and Computer \& Network Security are industries that have the highest need in UX designers and UX researchers. The study suggests higher education institutes especially mass communications programs may need to consider adopting the UX concept and skills into its teaching agenda.
\end{abstract}

Keywords: UX designer, UX researcher, job ads, content analysis, skills 


\section{Introduction}

User Experience (UX) is the latest and the hottest trend in the job market in recent years. The concept of UX has reached no consensus and it has been conceptualized in a variety of ways in the field of Human Computer Interaction $(\mathrm{HCl})$. $\mathrm{HCl}$ refers to the design and use of computer technology, which focuses on the interfaces between users and computers (Dix, 2009). There are five popular definitions of UX. The first one comes from International Organization for Standardization (ISO), which is an international standard-setting body composed of representatives from various national standards organizations. According to ISO (2010), UX is a person's perceptions and responses that result from the use or anticipated use of a product, system or service. The second definition comes from Norman, Miller and Henderson (1995), who posited that UX is all aspects of a person's experience with a system. The third definition comes from Nielsen and Norman (n.s), who defined UX as all aspects of the end user's interaction with the company, its services, and its products. The fourth definition comes from Alben (1996), who defined UX as users' sensations, understanding of how things work, feelings during usage, and achievements of goals under the overall interaction context. The fifth definition comes from Hassenzahl and Tractinsky (2006), who defined UX as a consequence of a user's internal state, the characteristics of the designed system, and the context within which the interaction occurs. This study adopts the definition from Nielsen and Norman (n.s.) by conceptualizing UX as all aspects of the end user's interaction with the company, its services, and its products as $\mathrm{UX}$ is treated more like an industry term and job title in this study.

According to glassdoor.com (2019), a UX designer makes an average of $\$ 90,000$ per year whereas a UX researcher makes an average of $\$ 93,152$ per year. Based on the latest job skills report released by LinkedIn, "UX" is ranked as the number five most desired hard skill by the companies in 2019 (Petrone, 2019). An average of 7,000 and 1,000 results could be generated using the keyword of "UX designer" and "UX researcher" in LinkedIn respectively via a random job search.

Due to the omnipresence of web in people's daily lives, it is impossible not to talk about UX in association with web design. In fact, the job title of "web designer" is reflected in many UX oriented job title configurations. For example, job titles such as "UX Designer," "User Interface Designer," "UX/UI Designer," "UX Engineer," "User Researcher," "UX Strategist," "Interaction Designer," and "Information Architect" can all be considered as equivalents of "web designer." Hence, many graphic/web designers decide to shift their 
career path to UX design because there are some shared skills between graphic designers and UX designers. For example, both graphic designers and UX designers master the skills of emotional design, creative thinking, and prototyping (Siang, 2018).

With the development of $\mathrm{UX}, \mathrm{HCl}$ has become a hot program in many American institutions of higher education. Carnegie Mellon University (CMU) established the Human-Computer Interaction Institute in 1993. Since then, the institute has graduated many students who work for big technology companies (CMU, 2019). Rutgers University offered the Human Computer Interaction bachelor's of science degree since 2006 (Rutgers, n.d.). Similarly, more and more journalism programs have started to embrace new technology products such as iPads to augment journalistic training (Kraft \& Seely, 2015). Columbia Journalism School has developed a dual master's degree program in Journalism and Computer Science to prepare students for opportunities in cross-disciplinary jobs such as designing and building platforms, natural language processing and the digital humanities. Ohio State University offers a New Media \& Communication Technology major and one of its tracks is Human Computer Interaction.

Traditional communication programs have been training the undergraduate students to work in the field of advertising, public relations, and journalism whereas the graduate students were trained to either work in the field of higher education or industry. Besides these traditional occupations, can undergraduate students be trained as future UX designers if they were asked to take a variety of design-oriented classes? Can graduate students be trained as future UX researchers if they were asked to take a variety of research-oriented classes? To answer these two broad questions, a content analysis study $(N=200)$ was conducted to examine the most desired UX design skills and the most desired UX research skills in the UX related job ads.

\section{Literature Review}

User Experience

Hassenzahl (2008) defined UX as "a momentary, primarily evaluative feeling while interacting with a product or service" (p. 12). A good UX is "the consequence of fulfilling the human needs for autonomy, competence, stimulation, relatedness, and popularity through interacting with the product or service" (p. 12). According to Hassenzahl and Tractinsky (2006), UX has three perspectives: instrumental, emotion/affect, and the experiential. In this study, UX would focus on generating supreme quality experiences rather than merely passing usability tests. 
In addressing "beyond the instrumental," Hassenzahl (2004) and Hassenzahl and Tractinsky (2006) distinguished between two quality perceptions: pragmatic and hedonic. Pragmatic quality refers to the product's ability to support the achievement of behavioral goals such as usefulness and ease of use. Hedonic quality refers to the users' self which consists of both stimulation and identification. Stimulation refers to the product's ability to stimulate and enable personal growth whereas identification refers to the product's ability to address the need of expressing one's self through objects one owns. Hassenzahl (2004) also suggested two distinct overall evaluative judgments of the quality of interactive products: beauty and goodness. He found goodness is affected by pragmatic aspect such as usefulness and usability while beauty is affected by identification.

Usability is a concept that is closely related to UX. According to ISO (2013), usability refers to the extent to which a product can be used by specified users to achieve specified goals with effectiveness, efficiency, and satisfaction in a specified context of use. The pursuit of effectiveness and efficiency belongs to pragmatic or instrumental qualities of a system whereas satisfaction taps into the hedonic quality of the system. Both usability and UX are considered as part of user centered design, which is an approach to interactive systems development that aims to make systems usable and useful (ISO, 2010).

Although UX stems from usability, the difference between the two is distinct. Usability focuses on an objective approach of the interaction whereas UX explores the subjective factors characterizing the experience between human and technology (Lallemand, Gronier, \& Koenig, 2015). Traditional usability studies have been focusing on user cognition and user performance in human technology interaction. In contrast, UX emphasis more on interaction by focusing on user affect, sensation, and the meanings as well as value of such interactions in everyday life (Law, Roto, Hassenzahl, Vermeeren, \& Kort, 2009).

Job Ads

Previous job ad studies have primarily examined the evolution of the skills in job ads (Todd, McKeen, \& Gallupe, 1995; Triumph \& Beile, 2015; Wenger, Owens, \& Cain, 2018). Todd et al. (1995) studied the evolution of the information system job skills from 1970 to 1990 in three types of jobs: programmers, system analysts, and information system managers. It is discovered that job ads for programmers have changed very little - technical requirements remain high, and business and systems knowledge requirements remain low. Triumph and Beile (2015) examined the skills needed in the academic library job market. Results showed there was a decline in foreign language 
skills and prior work experience requirements over time while computer skills were increasingly sought. Wenger et al. (2018) examined the skills needed in top U.S. news companies. Results showed there was an increase need in social media and audience engagement. There was also a significant trend toward seeking candidates who have the web/multimedia skills, teamwork, and the ability to work under pressure and tight deadlines.

Since UX is a relatively new and trendy concept, can anyone do UX related jobs as long as they have mastered the necessary skills? Previous literature suggested technical communicators could change their career path into UX (Lauer \& Brumberger, 2016). Lauer and Brumberger (2016) studied 502 industry jobs and found technical communication work shared traits and competencies with the field of UX. It is found that technical communicators who are not doing UX work could expand their career paths into the UX field and even play a central role in UX. In addition, result showed UX job postings could be broken down into five categories: designer, developer, architect, manager, and researcher. This finding is similar to Ozer and Cerci (2018)'s study where they found public relation is perceived as a profession that can be performed by both experienced and inexperienced people at every level of education and age.

This study chose Linkedln as a platform to collect the job ads as Linkedln is considered as one of the top four technology companies together with Google, Facebook, and Amazon in the United States and it is very inclusive in terms of providing the job ad information (Ritholtz, 2017).

\section{UX Design Skills}

As a UX designer, one has to master a range of design skills. In this study, a total of 21 design skills is examined from the job ads. These 21 design skills are collected based on the job description on the 100 UX designer job ads. These 21 design skills are Photoshop/Lightroom, Illustrator, InDesign, Adobe XD, InVision, Sketch, Axure, Justinmind, MockPlus, Balsamiq, Fluid UI, Omingraffle, HTML, CSS, JavaScript/JQuery, Dreamweaver, Backend Language (i.e. Python), After Effects, UserZoom, usertesting.com and Morae.

These 21 design skills can be divided into four groups: visual interface design (i.e. Photoshop), prototyping (i.e. InVision), coding (i.e. HTML), and usability testing (i.e. UserZoom). Visual interface design refers to any design software that can map out the visual appearance of an interface. For example, Photoshop, Lightroom, InDesign, and Illustrator can all fall under this umbrella. Prototyping belongs to the design thinking process where it allows designers to 
test design ideas in a quickly and timely fashion (Dam \& Siang, 2019). A prototype is a simple experimental model of a proposed solution used to test or validate ideas, design assumptions and other aspects of its conceptualization quickly and cheaply (Dam \& Siang, 2019). Coding refers to using both the front-end language (i.e. HTML, CSS) and the back-end language (i.e. Python) to make an interface available online (W3C, n.s.). Lastly, Usability testing is a way to see how easy to use an interface by testing it with real users (usability.gov, n.s.).

\section{UX Research Skills}

In the field of UX, there is a wide range of research methods available. As a UX researcher, one needs to master around 20 different research methods. According to Rohrer (2014), UX research methods can be summarized in three dimensions: attitudinal vs. behavioral, qualitative vs. quantitative, and context of use.

The first dimension is attitudinal vs. behavioral. The goal of attitudinal UX research is to understand or measure people's stated beliefs such as the survey method, which is heavily used in the marketing department. The goal of the behavioral UX research is to understand what people do with the product or service in use such as the eyetracking method, which can help examine how users visually interact with interface design (Rohrer, 2014). The second dimension is quantitative vs. qualitative. Quantitative methods can help answer how many and how much types of questions whereas qualitative methods can help answer questions about why or how to fix a problem (Rohrer, 2014). In other words, UX qualitative studies generate data about behaviors or attitudes based on observing them directly. UX quantitative studies provide data about the behavior or attitudes in question indirectly through a measurement or an instrument such as a survey or an analytic tool. Mixed method is a combination of both the qualitative methods and the quantitative methods. The third dimension is context of use which has to do with how and whether participants are using the product or the service. The context of use method can be classified into four phases: natural use of the product, scripted use of the product, not using the product during the study, and a hybrid of the above. The goal of the natural use of the product is to minimize interference to understand real behavior. The ethnographic field study is an example (Rohrer, 2014). A scripted study of product usage is to focus on the insights on specific usage aspects such as a newly redesigned flow study. (Rohrer, 2014). Studies where the product is not used are to examine issues that are broader than usage and usability such as a study of a brand or some cultural products. Hybrid methods use a creative form of product usage to meet their goals (Rohrer, 2014). For 
example, participatory-design methods allow users to create a new product experience by interacting with, re-arranging design elements so that they may discuss how their proposed solutions would better meet their needs and why they made certain choices (Rohrer, 2014).

Research Questions

Previous UX job ad research has examined the design skills needed for technical communication professionals to become UX designers (Lauer \& Brumberger, 2016). Previous study has also examined how communications students use interactive instructional technology from a user experience perspective (Wagler, 2019). However, few studies have examined the research skills needed to become UX researchers. Previous job ad studies have primarily investigated the evolution of the skills in job ads (Todd et al, 1995; Triumph \& Beile, 2015; Wenger et al., 2018). However, the assets (skill, major, degree) of becoming UX designers and UX researchers remain unknown. Thus, the following research questions are raised:

RQ1a: What assets (design skill, major, degree) are expected in UX designer job ads?

RQ1b: What assets (research skill, major, degree) are expected in UX researcher job ads?

Previous UX job ad research studied the industries that have the highest demand for UX jobs (Lauer \& Brumberger, 2016). It is found that IT Service/Software has the highest need in UX job. However, it is unclear which industry has the highest demand for UX designer and UX researcher respectively. Hence, the following research questions are posed:

RQ2a: Which industry has the highest demand for UX designers in the ads?

RQ2b: Which industry has the highest demand for UX researchers in the ads?

Previous UX job ad research examined the job locations of UX jobs and found that the positions were concentrated on the East and West Coasts (Lauer \& Brumberger, 2016). However, the job locations for UX designers and UX researchers remain unknown. Also, the job location study was conducted in 2016 or earlier, it is very likely that the job locations for UX designers and UX researchers may have shifted after three years. Thus, the following research questions are raised:

RQ3a: Which geographic areas (west, mid-west, south, northeast) have the highest demand for UX designers in the ads? 
RQ3b: Which geographic areas (west, mid-west, south, northeast) have the highest demand for UX researchers in the ads?

Since "design" is more emphasized among UX designers and "research" is more emphasized among UX researchers. Will there be any differences in terms of the degree requirements, geographic locations, and academic majors between UX designers and UX researchers? When people search for jobs on Linkedln, the job ad usually lists the posting time, company's name, and company's location. Will these factors influence the number of views on a job ad? Hence, the following two research questions are raised:

RQ4: How do the ads on UX designers and UX researchers differ in terms of degree requirements, geographic locations and academic majors?

RQ5: How do ads' posting time, ads' companies, and companies' location influence the number of views of the ads?

\section{Methods}

Sample

The study used the stratified sampling method to collect the sample. For UX researcher job ads, every five ads were selected using the keyword of "UX research" via the job search function on Linkedln. Similarly, every five ads were selected using the keyword of "UX design" to gather UX designer job ads on Linkedln. The two searches were completed during the same day. The selected ads were screen captured and saved as pictures in the PNG format. Overall, $100 \mathrm{UX}$ designer job ads and $100 \mathrm{UX}$ researcher job ads were collected from Linkedln.

\section{Measurements}

Asset

Asset is defined as useful and desirable quality based on the dictionary.com. In this study, asset is operationalized from three dimensions: skill, major, and degree.

Design skill

Design skill is measured by 21 dichotomous variables: Photoshop/Lightroom, Illustrator, InDesign, Adobe XD, InVision, Sketch, Axure, Justinmind, MockPlus, Balsamiq, Fluid UI, OminGraffle, HTML, CSS, Javascript/JQuery, Dreamweaver, backend language, After Effects, UserZoom, usertesting.com and Morae. If any one of the 21 design skills are mentioned in the job ad, it will be recorded as 1 (Yes). Otherwise, it will be recorded as 0 (No).

Research skill

Research skill includes six dimensions: behavioral qualitative, 
attitudinal qualitative, behavioral mixed, attitudinal mixed, behavioral quantitative, and attitudinal quantitative borrowed from Rohrer (2014). Research skills have a total of 20 dichotomous variables. See Table 1 for more details. If any one of the 20 research skills are mentioned in the job ad, it will be recorded as 1 (Yes). Otherwise, it will be recorded as 0 (No).

Major

Major is defined as an academic discipline where students can choose to stay focused on over a course of study at higher institutions. After reading all Linkedln job ads, major is measured with 12 dichotomous variables: Human Computer Interaction, Human factors, User Interaction Design, User Experience, Industrial Design, Graphic Design, Computer Graphic Design, Computer Science, Design, Psychology, Information Technology, and Anthropology. An "others" variable is added for those majors that did not fit into any of the above dichotomous variables. If any one of the 12 majors is mentioned in the job ad, it will be recorded as 1 (Yes). Otherwise, it will be recorded as 0 (No).

Degree

Degree is defined as an academic title conferred by colleges or universities after the completion of a course of study. Degree is measured at the nominal level with five levels: no degree, bachelor, master, doctorate, and degree required but there is no level specification.

Company's recognition

Company's recognition is a dichotomous variable with two levels: one level as a famous company or firm recognized by Fortune 500, and the other as an unknown company or firm not recognized by Fortune 500 .

Number of views

Number of views is presented on the job ad as an Arabic number located at the upper right corner.

Posting time

Posting time is measured at the ratio level by turning the time indicator of "how long ago" into total hours. For instance, if the time indicator says "one day ago," that would be coded as 24 .

Location

Location is measured with four levels: Northeast, Midwest, South, and West based on census regions/divisions of the United States.

Industry

Industry is measured with 15 dichotomous variables after reading all 200 job ads. These 15 industries are Higher Education, Information 
Technology and Service, Computer Software, Internet (including ecommerce), Electrical/Electronic manufacturing, machinery, industrial automation, consumer goods, health, wellness and fitness, cosmetics, finance/financial services/banking, marketing and advertising service, computing/network security and staffing and recruiting. "Others" is an additional variable for other industries. If any one of the 15 industries is mentioned in the job ad, it will be recorded as 1 (Yes). Otherwise, it will be recorded as 0 (No).

\section{Inter Coder Reliability}

Three coders (two faculties and one graduate student) coded the same 20 ads with ten on UX design and ten on UX research. The 20 ads were randomly selected from the 200 job ads sample. Three rounds of coder trainings were conducted. The final inter-coder reliability (Krippendorf's $\alpha$ ) for all variables ranged from.70 to 1 , which is acceptable. After that, the remaining job ads were distributed and coded by the three coders independently.

\section{Results}

\section{Sample Description}

A total of two hundred job ads $(N=200)$ were analyzed with 100 on UX designers and 100 on UX researchers. The average number of views in these ads was 66 times $(S D=135.18)$. The average posted time was 53 hours $(S D=70.24)$. The job level specified in the ads was primarily Manager or Senior (43.5\%), followed by Some Experience (42.5\%), Entry (12.5\%), and Director (1.5\%). Report Job Experience requirement listed in the job ads.

RQ1a asked what assets (design skill, major, degree) are expected for UX designers in the job ads. Before the analysis, four categories of design skills were created by sorting and combining the 21 dichotomous variables. Visual Interface Design was created by combining (i.e. averaging) Illustrator, Photoshop/Light Room, InDesign and Adobe Animate/After Effect; Prototyping was created by combining (i.e. averaging) Sketch, Adobe XD, InVision, Axure, Balsamiq, Omnigrapffle, JustinMind, and Mockuplus. Coding was created by combining (i.e. averaging) Dreamweaver, HTML, CSS, Javascript/JQuery, and back-end language. Usability Testing was created by combining (i.e. averaging) UserZoom, usertesting.com and Morae.

A one-way repeated measured ANOVA was conducted on the four categories of design skills to evaluate their differences. The results revealed significant differences among the four categories of design skills, Wilks' $\Lambda=.41, F(3,97)=45.87, p<.001$, partial $\eta^{2}=.59$. Follow-up comparisons suggested there was a similar demand for Visual Interface Design and Prototyping. Visual Interface Design ( $M$ 
$=1.77, S E=.18)$ was significantly more demanded than Coding $(M$ $=0.92, S E=.13, p<.001)$, and Usability Testing $(M=.02, S E=.01$, $p<.001)$; Usability Testing was the least demanded. Prototyping $(M$ $=1.52, S E=.15)$ was more demanded than coding $(M=.92, S E=.13$, $p<.01)$ than usability design $(M=.02, S E=.01, p<.001)$. Lastly, coding $(M=.92, S E=.13)$ was more demanded than usability design $(M=.02, S E=.01, p<.001)$. See Table 1 for details.

Table 1. Comparisons of indexed design skills demanded of UX designers.

\begin{tabular}{|c|c|c|c|c|c|}
\hline & $\begin{array}{l}\text { Visual } \\
\text { Interface } \\
\text { Design }\end{array}$ & Prototyping & Coding & $\begin{array}{l}\text { Usability } \\
\text { Testing }\end{array}$ & $\begin{array}{l}\text { One-way } \\
\text { Repeated } \\
\text { Measures } \\
\text { ANOVA }\end{array}$ \\
\hline $\begin{array}{r}\text { Visual Interface Design } \\
\qquad \begin{array}{r}(M=1.77, S E=.18) \\
\text { Prototyping } \\
(M=1.52 S E=.15) \\
\text { Coding } \\
(M=.92, S E=.13) \\
\text { Usability Testing } \\
(M=.02, S E=.01)\end{array}\end{array}$ & & n.s. & $\begin{array}{c}p<.001 \\
p<.01\end{array}$ & $\begin{array}{l}p<.001 \\
p<.001 \\
p<.001\end{array}$ & $\begin{array}{l}\text { Wilk's } \Lambda=.41 \\
F(3,97)=45.87 \\
p<.001 \\
\text { partial } \eta^{2}=.59\end{array}$ \\
\hline
\end{tabular}

A frequency test was performed to identify the top required design skills. Results showed Illustrator was ranked number one (54\%), followed by Photoshop/Light Room (53\%), and Sketch (46\%). Adobe XD (37\%) and Dreamweaver/HTML (37\%) tied at number four. InDesign (35\%) and Adobe Animate/After Effect (35\%) tied at number five. See Table 2 for details.

Table 2. Comparisons of specific design skills demanded of UX designers.

Visual Interface Design $(M=177, S D=1.16)$

\begin{tabular}{|c|c|c|}
\hline & $\begin{array}{l}\text { Illustrator Skill } \\
\text { Photoshop/Light Room Skill } \\
\text { InDesign Skill } \\
\text { Adobe Animate/After Effect }\end{array}$ & $\begin{array}{l}54 \% \\
53 \% \\
35 \% \\
35 \% \\
\end{array}$ \\
\hline $\begin{array}{r}\text { Prototyping } \\
(M=1.52, S D=1.54)\end{array}$ & $\begin{array}{l}\text { Sketch } \\
\text { Adobe XD } \\
\text { InVision } \\
\text { Axure } \\
\text { Balsamiq } \\
\text { Omnigraffle/JustinMind/Mockplus }\end{array}$ & $\begin{array}{l}46 \% \\
37 \% \\
29 \% \\
21 \% \\
11 \% \\
8 \% \\
\end{array}$ \\
\hline $\begin{array}{r}\text { Coding } \\
(M=.92, S D=1.29)\end{array}$ & $\begin{array}{l}\text { Dreamweaver/HTML } \\
\text { CSS } \\
\text { Javascript/JQuery }\end{array}$ & $\begin{array}{l}37 \% \\
33 \% \\
20 \%\end{array}$ \\
\hline
\end{tabular}


JOCTEC: Journal of Communication

Back-end language

$2 \%$

Usability Testing

$(M=.02, S D=.14)$

Usability Testing Skill

$2 \%$

Usertesting.com

$1 \%$

UserZoom

$1 \%$

Then, a frequency test was performed to identify the top required majors. Results showed Human Computer Interaction/User Interaction Design (39\%) was ranked as number one, followed by Design/Graphic Design/Computer Graphic Design (32\%), Computer Science (12\%), Human Factor (10\%). Industrial Design (6\%) and Information Technology (6\%) tied at number five. See Table 3. for details. Lastly, a frequency test was performed to identify the top required degrees. Results showed about $82 \%$ of the job ads require "No Degree at All" and about $18 \%$ of the job ads require the job seeker to have a bachelor's degree. There was no demand for master and PhD degrees. See Table 3 for details.

Table 3. Major and degree demands for UX designers and UX researchers.

\begin{tabular}{ll}
\hline Major Demands for UX Designers $(\boldsymbol{N}=\mathbf{1 0 0})$ & \\
Human Computer Interaction/User Interaction Design & $39 \%$ \\
Design/Graphic Design/Computer Graphic Design & $32 \%$ \\
Computer Science & $12 \%$ \\
Human Factor & $10 \%$ \\
Industrial Design & $6 \%$ \\
Information technology/science/system/design/architecture & $6 \%$ \\
Psychology & $4 \%$ \\
User Experience & $2 \%$ \\
\hline Degree Demands for UX Designers $(\boldsymbol{N}=\mathbf{1 0 0})$ & \\
No Degree & $82 \%$ \\
Bachelor's & $18 \%$ \\
Master's & $0 \%$ \\
PhD & $0 \%$ \\
\hline Major Demands for UX Designers $(\boldsymbol{N}=\mathbf{1 0 0})$ & \\
Human Computer Interaction & $61 \%$ \\
Psychology & $46 \%$ \\
Human Factor & $35 \%$ \\
Graphic Design & $19 \%$ \\
Information Technology & $16 \%$ \\
Anthropology & $12 \%$ \\
Computer Science & $8 \%$ \\
Industrial Design & $4 \%$ \\
User Experience & $3 \%$ \\
\hline Degree Demands for UX Designers $(\boldsymbol{N}=\mathbf{1 0 0})$ & \\
No Degree & $49 \%$ \\
Bachelor's & $27 \%$ \\
Master's & $17 \%$ \\
Ph.D. & $1 \%$ \\
Degree with no specification on levels & $6 \%$ \\
\hline & \\
& \\
\hline
\end{tabular}


RQ1b asked what assets (research skill, major, degree) are expected of UX researchers in the ads. Research skill is measured by 20 dichotomous variables. Six variables were created based on Rohrer (2014)'s categorization of user research methods: behavioral quantitative, attitudinal quantitative, behavioral qualitative, attitudinal qualitative, behavioral mixed, and attitudinal mixed. A one-way repeated measure ANOVA was performed on the six variables, and several significant differences were obtained, Wilks' $\Lambda=.55, F(5$, $95)=15.47, p<.001$, partial $\eta^{2}=.45$. Among the 15 pairwise comparisons, nine pairs were found to be significantly different from each other. Results showed Behavioral Mixed was the highest $(M=$ $.96, S E=.11)$. It was significantly higher than Attitudinal Mixed $(M=$ $.36, S E=.06)$ and Behavioral Quantitative $(M=.21, S E=.05)$. Behavior Qualitative was the second highest $(M=.89, S E=.09)$. It was significantly higher than Attitudinal Qualitive $(M=.58, S E=.08)$, Behavior Quantitative $(M=.21, S E=.05)$ and Attitudinal Mixed $(M=$ $.36, S E=.06)$. See Table 4 for details.

Table 4. Industry demands for UX designers and UX researchers.

\begin{tabular}{ll}
\hline $\boldsymbol{U}$ X Designers $(\boldsymbol{N}=\mathbf{1 0 0})$ & \\
Information Technology \& Services \& Computer \& Network Security & $59 \%$ \\
Computer Software & $37 \%$ \\
Internet (including e-commerce) & $21 \%$ \\
Finance, Financial Services, Banking & $15 \%$ \\
Marketing /Advertising Services & $13 \%$ \\
Health/Wellness \& Fitness/Cosmetics & $9 \%$ \\
Electrical/Electronic Manufacturing /Machinery/ Industrial Automation & $8 \%$ \\
Staffing and Recruiting & $4 \%$ \\
Consumer Goods & $2 \%$ \\
Higher Education & $1 \%$ \\
& \\
\hline $\boldsymbol{U} X$ Researchers $(\boldsymbol{N}=\mathbf{1 0 0})$ & \\
Information Technology \& Services \& Computer \& Network Security & $63 \%$ \\
Computer Software & $45 \%$ \\
Internet (including e-commerce) & $18 \%$ \\
Finance, Financial Services, Banking & $17 \%$ \\
Marketing /Advertising Services & $10 \%$ \\
Health/Wellness \& Fitness/Cosmetics & $8 \%$ \\
Staffing and Recruiting & $7 \%$ \\
Consumer Goods & $3 \%$ \\
Higher Education & $2 \%$ \\
Electrical/Electronic Manufacturing /Machinery/ Industrial Automation & $1 \%$ \\
\hline
\end{tabular}

A frequency test was performed to identify the top required research skills. The top four research skills were usability lab studies (55\%), moderated remote usability studies (47\%), usability benchmarking $(38 \%)$, and interviews (37\%). Ethnographic field studies and email survey tied at number five (34\%). A frequency test was performed to 
identify the top required majors. The top required major was $\mathrm{HCl}$ (61\%), followed by Psychology (46\%), Human Factor (35\%), Graphic Design (19\%), and Information Related Majors (16\%). See Table 4 for details. The degree required by UX researcher job ads had the following distribution: No degree (49\%), Bachelor's (27\%), Master's $(17 \%), \mathrm{PhD}(1 \%)$, and Degree required but no specification (6\%). See Table 5 for details.

Table 5. Comparisons of indexed research skills demanded for UX researchers.

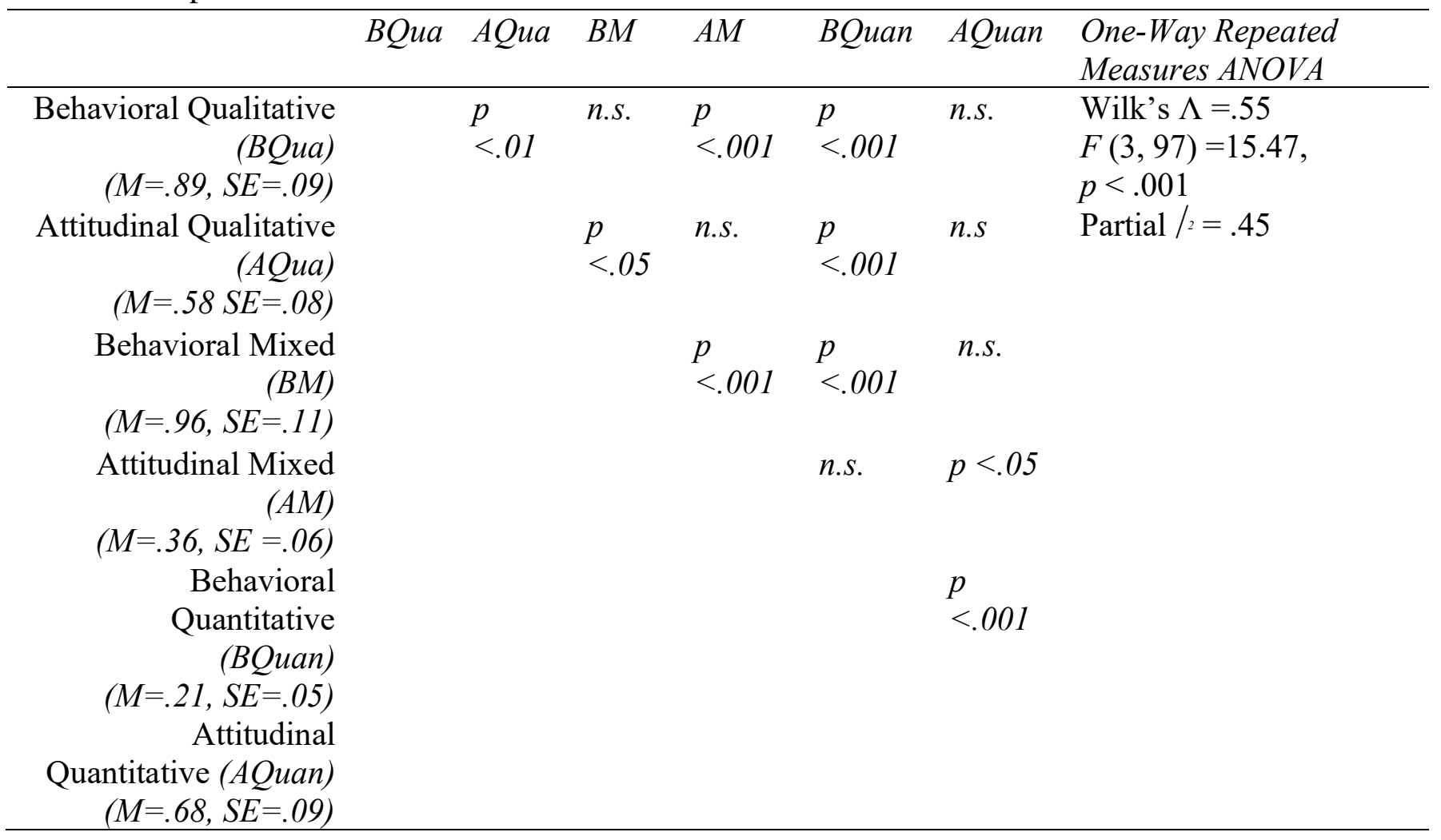

RQ2a asked which industry has the highest demand for UX designers in the ads.

A simple frequency test showed Information Technology and Services has the highest demand for UX designers (59\%), followed by Computer Software (37\%), Internet (including e-commerce) (21\%), Finance Service (15\%), Marketing and Advertising (13\%), Health and Wellness (9\%), Cosmetics (9\%), Electronical and Electronic Manufacturing (8\%), Consumer Goods (2\%), and Higher Education (1\%). See Table 6 for details.

Table 6. Comparison of research skills demanded of UX researchers.

Behavioral Qualitative $(M=.89, S D=.84)$

Usability lab studies $\quad 55 \%$

Ethnographic field studies $\quad 34 \%$

Behavioral Mixed

$(M=.97, S D=1.10)$

Moderated Remote Usability Studies $\quad 47 \%$ 
JoCTEC: Journal of Communication

Usability Benchmarking $\quad 38 \%$

Unmoderated Remote Panel Studies $\quad 10 \%$

Eye-tracking $2 \%$

Behavioral Quantitative

$(M=.21, S D=.51)$

\begin{tabular}{ll} 
A/B testing & $14 \%$ \\
Unmoderated UX studies & $4 \%$ \\
Clickstream analysis & $3 \%$ \\
True Intent studies & $0 \%$ \\
\hline
\end{tabular}

Attitudinal Qualitative

$(M=.57, S D=.81)$

interviews

$37 \%$

Focus groups $\quad 16 \%$

Participatory design $\quad 4 \%$

Attitudinal Mixed

$(M=.36, S D=.56)$

Card Sorting

$17 \%$

Concept testing

$10 \%$

Diary/Camera studies

$5 \%$

Customer Feedback

$0 \%$

Desirability studies

$0 \%$

Attitudinal Quantitative $(M=.67, S D=.93)$

Email surveys

$34 \%$

Intercept surveys

$33 \%$

RQ2b asked which industry has the highest demand for UX researchers in the ads.

A simple frequency test showed the highest demand industry for UX researchers are Information Related Industries (63\%), followed by Computer Software (45\%), Internet (18\%), Finance (17\%), Marketing and Advertising (10\%), Health and Wellness (8\%), Cosmetics (8\%), Staffing and Recruiting (7\%), Consumer Goods (3\%), Higher Education (2\%), and Electronical and Electronic (1\%). See Table 7 for details.

Table 7. Comparison of UX designers and UX researchers by geographic locations.

\begin{tabular}{llllll}
\hline & West & Mid-west & South & Northeast & \\
\hline UX Designers & $12.5 \%{ }^{\circ}$ & $9.0 \%{ }^{\text {a }}$ & $15.5 \%$ a & $13.0 \%{ }^{\text {a }}$ & $\chi^{2}(3, N=200)=10.71$ \\
UX Researchers & $21.5 \%$ ' & $11.0 \%{ }^{\text {a }}$ & $8.5 \%$ ' & $9.0 \%{ }^{\text {a }}$ & $p<.05$ \\
& $p<.05$ & & $p<.05$ & & \\
\hline
\end{tabular}

RQ3a asked which geographic areas have the highest demand for UX designers in the ads. A non-parametric Chi-square test was performed on the variable of geographic areas for the UX designer ads. It turned out that there were no significant differences among the four geographic areas. $X^{2}(3, N=100)=3.44, p=.33$. In other 
words, these four geographic areas: West $(25 \%)$, Midwest (18\%), South $(31 \%)$, and Northeast (26\%) have similar demands for UX designers.

RQ3b asked which geographic areas have the highest demand for UX researchers in the ads. A non-parametric Chi-square test was performed on the variable of geographic areas for the UX researcher ads. A significant difference among the four geographic areas was obtained: $X^{2}(3, N=100)=17.84, p<.001$. Specifically, the West has a significantly higher demand $(43 \%)$ for UX researchers than the other three areas. The South (17\%) and the Northeast (18\%) had a very similar demand. The Mid-West (22\%) is similar to the South $(17 \%)$ and the Northeast (18\%). See Table 8 for details.

Table 8. Comparison of UX designers and UX researchers by degree requirements.

No Bachelor Master/PhD Degree required but not

Degree clarified

\begin{tabular}{|c|c|c|c|c|c|}
\hline UX Designers & $41.0 \% \%^{\mathrm{a}}$ & $9.0 \% 0^{\mathrm{a}}$ & 0 a & 0 a & $\begin{array}{l}\chi^{2}(4, N=200)= \\
34.11,\end{array}$ \\
\hline \multirow{2}{*}{$\begin{array}{l}\text { UX } \\
\text { Researchers }\end{array}$} & $24.5 \%{ }^{\mathrm{b}}$ & $13.5 \%{ }^{\mathrm{a}}$ & $9.0 \%$ & $3.0 \%$ & $p<.001$ \\
\hline & $p<.05$ & & $p<.05$ & $p<.05$ & \\
\hline
\end{tabular}

RQ4 asked how do the ads on UX designers and UX researchers differ in terms of degree requirements, geographic locations and academic majors? Chi-square tests were performed on degree requirements for $U X$ designers and $U X$ researchers and a significant difference was obtained, $\mathrm{X}^{2}(4, N=200)=34.11, p<.001$. It is found that "no degree" was significantly much more for UX designers (41\%) than for UX researchers (24.5\%). Master/PhD degrees was significantly more demanded for UX researchers (9\%) than for UX designers $(0 \%)$. "Degree without specification" was significantly more demanded of researchers $(3 \%)$ than for designers $(0 \%)$. In general, degrees were more demanded of UX researchers than of UX designers. See Table 9 for details. For the differences among geographic locations, the Chi-Square test was performed and over all there was a significant difference, $X^{2}(3, N=200)=10.71, p<.05$. Specifically, the West demanded more UX researchers $(21.5 \%)$ than UX designers (12.5\%). The South was the opposite - the South demanded more designers (15.5\%) than the researchers $(5.5 \%)$. The other two regions - the Northeast and the Mid-West had the similar demands. See Table 9 for details.

Table 9. Comparison of UX designers and UX researchers by majors. 


\begin{tabular}{|c|c|c|c|}
\hline & Human Compu & action & \\
\hline & Yes & No & $\chi^{2}(1, N=200)=15.73, p<.001$ \\
\hline UX Designers & $11.5 \% \%^{\mathrm{a}}$ & $38.5 \%$ & \\
\hline \multirow[t]{3}{*}{ UX Researchers } & $25.0 \% \mathrm{o}^{\mathrm{b}}$ & $25.0 \%$ & \\
\hline & Human Factor & & \\
\hline & Yes & No & $\chi^{2}(1, N=200)=15.67, p<.001$ \\
\hline UX Designers & $5.0 \% 0^{\mathrm{a}}$ & $45.0 \% 0^{\mathrm{a}}$ & \\
\hline \multirow[t]{3}{*}{ UX Researchers } & $16.5 \%{ }^{\mathrm{b}}$ & $33.5 \%$ & \\
\hline & Design & & \\
\hline & Yes & & $\chi^{2}(1, N=200)=3.88, p<.05$ \\
\hline UX Designers & $8.0 \% 0^{\mathrm{a}}$ & $42.2 \%$ & \\
\hline \multirow[t]{3}{*}{ UX Researchers } & $3.5 \%$ & $46.2 \%{ }^{\mathrm{b}}$ & \\
\hline & Psychology & & \\
\hline & Yes & No & $\chi^{2}(1, N=200)=47.04, p<.001$ \\
\hline UX Designers & $2.0 \% 0^{\mathrm{a}}$ & $48.0 \% 0^{\mathrm{a}}$ & \\
\hline \multirow[t]{3}{*}{ UX Researchers } & $23.0 \%{ }^{\mathrm{b}}$ & $27.0 \%{ }^{\mathrm{b}}$ & \\
\hline & Information Te & ce System/Architecture & \\
\hline & Yes & No & $\chi^{2}(1, N=200)=5.11, p<.05$ \\
\hline UX Designers & $3.0 \% 0^{\mathrm{a}}$ & $47.0 \% 0^{\mathrm{a}}$ & \\
\hline \multirow[t]{3}{*}{ UX Researchers } & $8.0 \%$ & $42.0 \% \mathrm{o}^{\mathrm{b}}$ & \\
\hline & Anthropology & & \\
\hline & Yes & No & $\chi^{2}(1, N=200)=12.77, p<.001$ \\
\hline UX Designers & $0^{a}$ & $50.0 \%{ }^{\mathrm{a}}$ & \\
\hline UX Researchers & $6.0 \% 0^{\mathrm{b}}$ & $44.0 \%{ }^{\mathrm{b}}$ & \\
\hline
\end{tabular}

Notes: $\mathrm{N}=200 .{ }^{*} \mathrm{p}<.05$.

When it comes to comparing major for UX designers and UX researchers, a series of Chi-Square tests were performed. The results showed six significant majors: $\mathrm{HCl}, \mathrm{X}^{2}(1, N=200)=15.73, p$ $<.001$; Human Factor, $\mathrm{X}^{2}(1, N=200)=15.67, p<.001$; Design, $\mathrm{X}^{2}$ $(1, N=200)=3.88, p<.05 ;$ Psychology, $x^{2}(1, N=200)=47.04, p<$ .001; Information Technology/Science System Design/Architecture, $\mathrm{X}^{2}(1, N=200)=5.11, p<.05$; and Anthropology, $\mathrm{X}^{2}(1, N=200)=$ $12.77, p<.001$. While the design major was significantly more desirable for UX designers, the other five majors $(\mathrm{HCl}$, Human Factor, Psychology, Information, Anthropology) were significantly more desirable for UX researchers.

RQ5 asked how do ads' posting time, ads' companies, and companies' location influence the number of views on the job ads. A multiple regression analysis was performed. The results showed a significant model, adjusted $R^{2}=.06, F(5,194)=2.30, p<.05$. 
Specifically, both posting time $(\beta=.16, p<.05)$ and the geographic location of the South $(\beta=-.16, p<.05)$ significantly predicted the number of views on the job ads. This suggested the longer the ad was posted, the higher the job views. The dichotomous variable South worked in a reverse way. When the ad companies' locations were not in the South, the higher the job views. However, it is worth to point out that the regression model's explaining power is not that great in that only $6 \%$ of the variance of views could be explained by the model. See Table 10 for details.

Table 10. Standardized regression coefficients predicting number of views of ads from ads' posting time, ad companies' and companies' location.

\begin{tabular}{llll}
\hline & $B$ & $S E$ & $\beta$ \\
\hline Companies' Recognition & 4.83 & 23.49 & .02 \\
Posting Time & .312 & .135 & $.16^{*}$ \\
Midwest & 12.987 & 26.571 & -.04 \\
South & -50.847 & 25.284 & $-.16^{*}$ \\
Northeast & 27.468 & 25.763 & .08 \\
Adjusted $R^{2}$ & .063 & & \\
$F$ & 2.596 & & \\
\hline
\end{tabular}

Note. $\mathrm{N}=200$. The same columns with different superscripts ${ }^{\mathrm{a}}$ and ${ }^{\mathrm{b}}$ mean they are significantly different at .05 .

\section{Discussion}

This study examined the design skills and research skills expected for the UX designers and the UX researchers in 200 job ads collected from Linkedln. This study is unique in that it focused on examining the specific design skills and research skills required for the UX designers and UX researchers, which may be beneficial for future graduates of the communication major. Since most communication major students were trained to work in the field of higher education, this study may provide another different insight for the communication major students to choose a career path in UX design or UX research. While a previous study suggested technical communication could be transformed into UX related jobs (Lauer \& Brumberger, 2016), the current study implied mass communication programs can easily integrate UX related courses to tailor to the UX market needs. In sum, the study concluded that a diverse range of skills were essential to UX designers and UX researchers; humancomputer interaction major is in highest demand of current UX designers; UX researchers has a higher demand of degrees than UX designers; the information related industries, computer software industry and internet industry all crave for UX designers and UX researchers; the West geographic area needs more UX researchers and the South needs more UX designer.

For UX designer, visual interface design is the most desired design skill, followed by prototyping, coding, and usability testing. Within 
visual interface design, Illustrator is the most desired design skill. The reason is probably because Illustrator is a vector shape design skill widely used to create logos and illustrations. Mastering this software might be quite helpful when it comes to designing the user interface (UI) for web and mobile applications. Within prototyping, AdobeXD is the most desired design skill. It is probably because AdobeXD allows users to come up with a quick prototyping without mastering the coding skills. Within coding, Dreamweaver/HTML is the most desired skill. This finding is not surprising in that HTML is a basic coding skill toward web designers. This array of design skills is mostly covered in current mass communication programs suggesting an easy transition or integration into an UX oriented program.

Another finding that may help this transition is based on the most frequently mentioned majors: $\mathrm{HCl} /$ User Interaction Design and Design. Current mass communication programs would definitely be more appealing to students if $\mathrm{HCl}$ related courses can be created and integrated in the curriculum. Another interesting finding from this study is that job candidates do not need to pursue an advanced degree to become UX designers. Only 18 percent of the UX designer job ads required bachelor's degree whereas nearly 82 percent of the UX designer job ads do not require any degree at all. This finding suggested that creating UX design skills classes and encourage students to take them is more important than creating and developing the UX oriented degrees.

For UX researcher job ads, the behavioral mixed method and the behavioral qualitative method are two of the most desired research skills. In a nutshell, usability lab studies, moderated remote usability studies, usability benchmarking studies, interviews, ethnographic field studies, and email surveys are the top six desired research methods for UX researchers. It suggests that the mass communications program should not dichotomize students' training to be either a quantitative scholar or qualitative scholar. Instead, it should train students both ways and encourage them to be proficient in the mixed method so that they may have a better chance in becoming a UX researcher. Similar to UX designers, HCI/User Interaction Design is the most frequently mentioned major in the job ads for UX researchers. The second most frequently mentioned major for UX researchers is psychology. Maybe the mass communications programs should integrate some "Psychology" related courses in transforming into UX research-oriented programs. The mass communication programs should also offer courses targeting at $\mathrm{HCl}$, user interface design. Different from the UX designer job ads, the UX researcher job ads have a higher degree requirement. About 27 percent of the job ads mentioned the job candidate needs to have a bachelor's degree. About 17 percent of 
the job ads mentioned the job candidate needs to have a master's degree. Thus, students should be encouraged to pursue an advanced degree if they want to become a UX researcher.

Other interesting findings emerged from this study are the industry and the geographic location for the UX designers and UX researchers. Information Technology \& Service (59\%), and Computer \& Network Security (63\%) are the two industries that have the highest need in UX designers and UX researchers. This finding is consistent with Lauer and Brumberger (2016)'s study which found IT service/Software had the highest demand in UX jobs. For geographic locations, the South (15.5\%) has the highest need for UX designers whereas the West $(21.5 \%)$ has the highest need for UX researchers. This finding is slightly different from Lauer and Brumberger (2016)'s study where the UX job positions were concentrated on the East and the West Coasts in the United States. Another interesting finding showed the job posting time and the geographic location of the Northeast were two significant predictors of the number of views on a job ad. Specifically, the longer the job ad is posted, the more views it will gather. When the job location was not located in the South, the job ad generated more views.

This study is not without limitations. First, the sample size of the study is relatively small, future study could collect more job ads to increase its external validity. Second, this study only collected job ads from Linkedln, other popular job platforms such as indeed.com and monster.com may have more UX related jobs and provide more solid conclusions. Future study could collect job ads across multiple job searching platforms and to see if differences among the job posting platforms will emerge. Third, this study primarily examined the hard skills required for UX researchers and UX designers, future study could also study the soft skills such as personality, management skills, communication skills, and leadership skills between these two types of jobs to provide a more comprehensive picture. Lastly, this study takes a very broad and general approach to content analyzing all aspects of job descriptions of UX designers and $U X$ researchers. The suggested transition to $U X$ related courses is only speculation at most. It would be helpful to survey the current mass communications programs to identify the current course offerings to see where the mass communication programs are in terms of integration of UX skills. 
Dr. Ruoxu Wang (PhD, Penn State University) is an Assistant Professor of advertising at the Department of Journalism and Strategic Media, University of Memphis. Dr. Wang's research interests lie on the intersection of media effects and persuasion under the context of strategic communication and communication technology.

Dr. Jin Yang (Ph. D., Southern Illinois University) is a full professor of journalism and creative mass media at the Department of Journalism \& Strategic Media, University of Memphis. Dr. Yang's research focuses on comparative media coverage, journalism education, and communication technology.

Louis Asser completed his Master of Arts at the University of Memphis in December of 2019, majoring in Journalism and Strategic Media. Asser has recently been employed by Embassy Row as a development analyst where he will work on sports programming including Good Morning Football and Men in Blazers. 


\section{References}

Alben, L. (1996). Quality of experience: Defining the criteria for effective interaction design. Interactions, 3(3), 11-15. https://doi.org/10.1145/235008.235010

Carnegie Mellon University. (2019). About the Human Computer Interaction Institute. Retrieved from https://hcii.cmu.edu/about

Dam, R. \& Siang, T. (2019). Design thinking: Get started with prototyping. Retrieved from https://www.interaction-design.org/literature/article/designthinking-get-started-with-prototyping

Dix, A. (2009). Human-Computer Interaction. (pp. 1327-1331). Springer US.

Glassdoor. (2019). UX designer salaries and UX researcher salaries. Retrieved from https://www.glassdoor.com/Salaries/ux-designer-salary-SRCH_KO0,11.htm

Hassenzahl, M. (2008, September). User experience (UX): Towards an experiential perspective on product quality. In IHM (Vol. 8, pp. 11-15).

Hassenzahl, M. (2004). The interplay of beauty, goodness, and usability in interactive products. Human-Computer Interaction, 19(4), 319-349. https://doi.org/10.1207/s15327051hci1904_2

Hassenzahl, M., \& Tractinsky, N. (2006). User experience - A research agenda. Behaviour \& Information Technology, 25(2), 91-97. https://doi.org/10.1080/01449290500330331

ISO. (2010). Ergonomics of human-system interaction - Part 210: Humancentred design for interactive systems. Retrieved from https://www.iso.org/obp/ui/\#iso:std:iso:9241:-210:ed-1:en

ISO. (2013). Usability of consumer products and products for public use - Part 2: Summative test method. Retrieved from https://www.iso.org/obp/ui/\#iso:std:iso:ts:20282:-2:ed-2:v1:en

ISO. (2013). Usability of consumer products and products for public use - Part 2: Summative test method. Retrieved from https://www.iso.org/obp/ui/\#iso:std:iso:ts:20282:-2:ed-2:v1:en

Kraft, N., \& Seely, N. (2015). Making mojos: How iPads are enhancing mobile journalism education. Journalism \& Mass Communication Educator, 70(3), 220234. https://doi.org/10.1177/1077695815596493

Kratz, G. (2018). Why use Linkedln. Here are 7 reasons. Retrieved from https://www.flexjobs.com/blog/post/why-use-linkedin-reasons/

Lauer, C., \& Brumberger, E. (2016). Technical communication as user experience in a broadening industry landscape. Technical Communication, 63(3), 248-264.

Lallemand, C., Gronier, G., \& Koenig, V. (2015). User experience: A concept without consensus? Exploring practitioners' perspectives through an international survey. Computers in Human Behavior, 43, 35-48. https://doi.org/10.1016/j.chb.2014.10.048 
Law, E. L. C., Roto, V., Hassenzahl, M., Vermeeren, A. P., \& Kort, J. (2009). Understanding, scoping and defining user experience: a survey approach. In Proceedings of the SIGCHI Conference on Human Factors in Computing Systems (pp. 719-728).

Norman, D., \& Nielsen, J. (n.s.). The definition of user experience (ux). Retrieved from https://www.nngroup.com/articles/definition-user-experience/

Norman, D., Miller, J., \& Henderson, A. (1995, May). What you see, some of what's in the future, and how we go about doing it: $\mathrm{HI}$ at Apple Computer. In Conference Companion on Human Factors in Computing Systems (p. 155). ACM.

Özer, d., \& Çerçi, Ü. Ö. (2018). Perceived image of public relations job advertisements by employers and a critical approach. Global Media Journal: Turkish Edition, 8(16).

Petrone, P. (2019). The skills companies need most in 2019 - And how to learn them. Retrieved from https://www.linkedin.com/pulse/skills-companies-needmost-2019-how-learn-them-paul-petrone/

Rutgers University (n. d.). Human-Computer Interaction 531. Retrieved on May 31, 2020 from http://catalogs.rutgers.edu/generated/nwk-ug_0608/pg23312.html

Ritholtz, B. (2017). The big four of technology. Retrieved from https://www.bloomberg.com/opinion/articles/2017-10-31/the-big-four-oftechnology

Rohrer, C. (2014). When to use which user-experience research methods. Retrieved from https://www.nngroup.com/articles/which-ux-research-methods/

Siang, T. (2019). How to change your career from graphic design to UX design. Retrieved from https://www.interaction-design.org/literature/article/how-tochange-your-career-from-graphic-design-to-ux-design

Todd, P. A., McKeen, J. D., \& Gallupe, R. B. (1995). The evolution of IS job skills: A content analysis of IS job advertisements from 1970 to 1990. MIS Quarterly, 127. https://doi.org/10.2307/249709

Triumph, T. F., \& Beile, P. M. (2015). The trending academic library job market: An analysis of library position announcements from 2011 with comparisons to 1996 and 1988. College \& Research Libraries, 76(6), 716-739. https://doi.org/10.5860/crl.76.6.716

Usability.gov. (n.s.). User experience basics. Retrieved from https://www.usability.gov/what-and-why/user-experience.html

W3C. (n.s.). HTML \& CSS. Retrieved from https://www.w3.org/standards/webdesign/htmlcss

Wagler, A. (2019). Understanding of how communications students use interactive instructional technology from a user experience perspective. Journalism \& Mass Communication Educator, 74(1), 7991.https://doi.org/10.1177/1077695818777413 
JoCTEC: Journal of Communication

Wenger, D. H., Owens, L. C., \& Cain, J. (2018). Help wanted: Realigning journalism education to meet the needs of top US news companies. Journalism \& Mass Communication Educator, 73(1), 18-36. https://doi.org/10.1177/1077695817745464

To cite this article:

Wang, R., Yang, J., \& Asser, L. (2021). User experience (UX) matters: What are the most desired skills in the UX designer and UX research job ads. Journal of Communication Technology, 4(2), 82105. DOI: $10.51548 /$ ioctec-2021-011. 